\title{
Improved salinity tolerance in early growth stage of maize through salicylic acid foliar application
}

\author{
Iqra Sultan, ${ }^{1}$ Imran Khan, ${ }^{2}$ Muhammad Umer Chattha, ${ }^{2}$ Muhammad Umair Hassan, ${ }^{2}$ \\ Lorenzo Barbanti, ${ }^{3}$ Roberta Calone, ${ }^{3}$ Muqarrab Ali, ${ }^{4}$ Shahid Majeed, ${ }^{5}$ Muhammad Awais \\ Ghani, ${ }^{6}$ Maria Batool, ${ }^{7}$ Warda Izzat, ${ }^{1}$ Sajid Usman ${ }^{8}$ \\ ${ }^{1}$ Department of Botany, University of Agriculture, Faisalabad, Pakistan; ${ }^{2}$ Department of Agronomy, \\ University of Agriculture, Faisalabad, Pakistan; ${ }^{3}$ Department of Agricultural and Food Sciences, University \\ of Bologna, Italy; ${ }^{4}$ Department of Agronomy, Muhammad Nawaz Sharif University of Agriculture, Multan, \\ Pakistan; ${ }^{5}$ Department of Entomology, University of Agriculture, Faisalabad, Pakistan; ${ }^{6}$ Institute of \\ Horticultural Sciences, University of Agriculture, Faisalabad, Pakistan; ${ }^{7}$ College of Plant Science and \\ Technology, Huazhong Agricultural University, Wuhan, China; ${ }^{8}$ Institute of Soil and Environmental \\ Sciences, University of Agriculture, Faisalabad, Pakistan
}

\section{Highlights}

Foliar applied salicylic acid alleviated salinity effects on maize growth at early plant stage.

Salicylic acid improved leaf water status, chlorophyll content, and strengthened anti-oxidant enzymes under salinity.

Salicylic acid reduced oxidative stress markers while enhancing osmo-regulating and hormonal responses to salinity.

Salicylic acid hampered $\mathrm{Na}$ and $\mathrm{Cl}$ entry and translocation to above ground organs, preserving leaf cell membrane integrity.

Salicylic acid was shown beneficial for maize growth and physiology also under non-saline conditions.

\begin{abstract}
Soil salinity threatens agricultural production worldwide by constraining plant growth and final crop yield. The early stages are most sensitive to salinity, in response to which salicylic acid (SA) has demonstrated beneficial effects in various plant species. Based on this, a maize (Zea mays L.) pot experiment was set up combining three levels of soil salinity $\left(0,6\right.$ and $\left.12 \mathrm{dS} \mathrm{m}^{-1}\right)$, obtained through $\mathrm{NaCl}$ addition, with three levels of SA $(0,300$ and $600 \mathrm{mM}$ ), applied by leaf spraying 20 days after seedling
\end{abstract}

Correspondence: Lorenzo Barbanti, Department of Agricultural and Food Sciences, University of Bologna, viale Giuseppe Fanin 44, 40127 Bologna, Italy. E-mail: lorenzo.barbanti@unibo.it

Key words: Anti-oxidants; hormones; ionic homeostasis; maize; salicylic acid; salinity.

See online Appendix for additional Tables and Figures.

Received for publication: 19 January 2021.

Revision received: 22 March 2021.

Accepted for publication: 22 March 2021.

(C) Copyright: the Author(s), 2021

Licensee PAGEPress, Italy

Italian Journal of Agronomy 2021; 16:1810

doi:10.4081/ija.2021.1810

This article is distributed under the terms of the Creative Commons Attribution Noncommercial License (by-nc 4.0) which permits any noncommercial use, distribution, and reproduction in any medium, provided the original author(s) and source are credited. emergence. Fifteen days later, the following traits were assessed: morphology (plant height, leaf number), growth (root and shoot dry weight), leaf water status [relative water content (RWC), electrolyte leakage (EL)], pigments (chlorophyll $a$ and $b$, carotenoids, anthocyanin), antioxidant enzymes (peroxidase, catalase, ascorbate peroxidase, vitamin $\mathrm{C}$ ), oxidative stress markers $\left(\mathrm{H}_{2} \mathrm{O}_{2}\right.$, malondialdehyde), osmo-regulating compounds (free amino acids, soluble proteins and sugars, proline), hormones [indole-3-acetic acid, gibberellic acid (GA), abscisic acid (ABA), ethylene], element $(\mathrm{Na}, \mathrm{K}, \mathrm{Ca}, \mathrm{Mg}$ and $\mathrm{Cl})$ concentration and content in roots, stem and leaves. Salinity severely affected maize growth $(-26 \%$ total dry weight), impaired leaf water status $(-31 \%$ RWC), reduced photosynthetic pigments, enhanced all antioxidant enzymes and oxidative stress markers, two osmo-regulating compounds (soluble sugars and proline) out of four, and all hormones except GA. SA was shown effective in containing most of the stress effects, while supporting plant defences by upgrading antioxidant activities (reduced oxidative stress markers), increasing cell membrane stability $(-24 \%$ EL) and leaf water status $(+20 \%$ RWC), and reducing plant stress signalling ( $-10 \%$ ABA and $-20 \%$ ethylene). Above all, SA contrasted the massive entry of noxious ions $\left(\mathrm{Na}^{+}\right.$and $\left.\mathrm{Cl}^{-}\right)$, in favour of $\mathrm{K}^{+}, \mathrm{Ca}^{2+}$ and $\mathrm{Mg}^{2+}$ accumulation. Lastly, salicylic acid was shown beneficial for maize growth and physiology also under non-saline condition, suggesting a potential use in normal field conditions.

\section{Introduction}

Salinity affects soil fertility and crop productivity across the world (Deinlein et al., 2014), and a crop surface of 830-950 million ha is estimated to suffer salinity stress, to a variable extent around the globe (Flowers and Colmer, 2015). More to this, limited irrigation, salty water, and poor drainage fuel the increase of 
saline soils predominantly in the arid and semi-arid world areas (Cassaniti et al., 2013). Lastly, at a global scale and on a yearly basis, salinity stress causes a 12 billion US dollars reduction in agricultural production (Qadir et al., 2014), and puts $1.5 \mathrm{~m}$ ha out of cultivation (Munns and Tester, 2008).

Salinity causes ionic, oxidative, and osmotic stress to plants; all of them can have devastating impacts on diverse physiological and metabolic processes (Flower and Colmer, 2008). Plant responses to these changes often result in various alterations including the reduction in leaf area, internode length, and leaf necrosis and final abscission (Parida and Das, 2005). The response of plants and their ability to tolerate the salinity stress varies significantly among species (Flower and Colmer, 2008). Salinity stress disturbs the normal photosynthetic and respiration processes, as well as starch metabolism (Sudhir and Murthi, 2004). Additionally, it significantly reduces the amount of the photosynthetic pigments (Juan et al., 2005), and affects the production and accumulation of different hormones in plants. Ethylene is considered the most important hormone, as it influences several physiological processes, root growth, stem elongation, fruit ripening and grain development (Hussain et al., 2019). Ethylene production significantly increases under salt stress, which leads to a substantial reduction in growth and physiological processes (Hussain et al., 2020a). Thus, it is of primary importance for the plant to maintain low ethylene accumulation under salt stress in order to ensure better growth.

The uptake of large amounts of ions results in increased osmotic pressure at cellular level. Therefore, plants maintain cell homeostasis by sequestering salt ions in the vacuoles or by accumulating variable organic osmolytes (Munns, 2002). Moreover, in different plant species, various osmolytes such as proline or soluble sugars are produced, which protect plant cells from the damaging effects of salinity stress. Higher proline accumulation is often linked with salt tolerance (Hokmabadi et al., 2005). Therefore, plant ability to accumulate proline is often suggested as criteria to select salt tolerant genotypes (Ashraf and Harris, 2004).

The $\mathrm{Na}$ and $\mathrm{K}$ homeostasis plays an indispensable role in plant growth owing to the fact that the interaction between the two cations is mostly responsible for $\mathrm{K}$ deficiency (Parida and Das, 2005; Rahneshan et al., 2018). Potassium is fundamental for various physiological processes including enzymatic activation, maintenance of osmotic pressure and turgor potential, and stomatal opening (Golldack et al., 2003). Therefore, a higher K:Na ratio results in higher salt tolerance (Raza et al., 2007). Moreover, $\mathrm{Ca}$ also plays a relevant role in salt tolerance, as it controls $\mathrm{Na}$ influx by non-selective ionic channels, and therefore, alleviates salinity toxic effects (Melgar et al., 2006).

Plants produce diverse signalling molecules under salt stress, which diminish the negative effects and improve plant resilience facing this stress. Salicylic acid (SA) is one of the most important signalling molecules: its role in increasing plant adaptation to salt stress is well documented (Dempsey and Klessig, 2017; Kudla et al., 2018). In fact, SA influences a vast array of plant processes from seed germination to growth, and improves the salt tolerance by increasing the endogenous SA level (El-Mergawi and El-Wahed 2020). Specifically, SA has been found to increase salt tolerance by increasing membrane stability and photosynthetic efficiency (ElTayeb, 2005; Al-Whaibi et al., 2012). Moreover, SA stimulates the activity of various antioxidant enzymes, reduces the accumulation of $\mathrm{Na}^{+}$and $\mathrm{Cl}^{-}$and induces the increase in endogenous SA which in turn improves salt tolerance (Jini and Joseph, 2017; Kim et al., 2017). SA application also increases the accumulation of osmolytes as soluble proteins and soluble sugars, and maintains the optimum K:Na ratio (Ashraf et al., 2010; Hayat et al., 2010; Kim et al., 2017). SA also reduces the lipid peroxidation and production of reactive oxygen species, and interacts with different hormones to increase plant tolerance to salinity (Jayakannan et al., 2015; Husen et al., 2018). Likewise, SA application increases the synthesis of indole-3-acetic acid (IAA) and gibberellic acid (GA), two hormones also contributing to plant growth under salt stress (Shaki et al., 2019). Therefore, all these characteristics make SA a key substance to improve plant tolerance to salinity.

Maize (Zea mays L.) is the second largest cereal crop at world level (FAO, 2019), and is a species quite sensitive to salinity (Rhoades et al., 1992). Owing to this, it is expected that maize could remarkably benefit from treatment with SA. In contrast to this, there is a paucity of knowledge related to the effects of SA on ionic homeostasis and SA cross talk with various hormones, especially abscisic acid and ethylene; these are the premises for effective use of SA in plants as maize. To fill this gap of knowledge, we hypothesized that SA could diminish the various effects of salinity since an early stage of the maize plant. Consequently, the present study was conducted to determine the effects of SA application on maize early growth, physiological attributes, anti-oxidant activity, osmolyte accumulation, ionic homeostasis, and SA mediated hormonal cross talk under salinity.

\section{Materials and methods}

\section{Experiment set up}

A pot experiment was conducted at the University of Agriculture, Faisalabad, Pakistan. The soil was collected from the Agronomy experimental farm $\left(31.8^{\circ} \mathrm{N}, 73.8^{\circ} \mathrm{E}, 184 \mathrm{~m}\right.$ a.s.1.), airdried, mixed, sieved, and subjected to determination of the principal soil properties: the soil was a clay loam with $\mathrm{pH} 7.65$, organic matter $6.5 \mathrm{mg} \mathrm{g}^{-1}$, Kjeldahl N $0.38 \mathrm{mg} \mathrm{g}^{-1}, \mathrm{C}: \mathrm{N} 9.9$, available P 13 $\mathrm{mg} \mathrm{kg}{ }^{-1}$, and exchangeable $\mathrm{K} 171 \mathrm{mg} \mathrm{kg}^{-1}$. Twenty-seven pots were filled each with $8 \mathrm{~kg}$ of soil. Maize seeds were sterilized for 1 minute with $70 \%$ ethanol followed by sodium hypochlorite for 5 minutes; at the end, seeds were washed with distilled water $\left(\mathrm{dH}_{2} \mathrm{O}\right)$ five times and dried. Thereafter, 10 seeds per pot were sown at 1.5 $\mathrm{cm}$ depth. The study was conducted from $1^{\text {st }}$ March to $15^{\text {th }}$ April 2018 under a transparent rain shelter. During this period, the average minimum and maximum daily temperature was $17.4^{\circ} \mathrm{C}$ and $32.4^{\circ} \mathrm{C}$, respectively. Air humidity varied between $43 \%$ and $73 \%$. The pots were regularly watered according to need.

\section{Experimental treatments}

Nine treatments were set up resulting from the cross combination of three soil salinity levels, control, $6 \mathrm{dS} \mathrm{m}^{-1}$ and $12 \mathrm{dS} \mathrm{m}^{-1}$, and three SA levels, control, $300 \mathrm{mM}$ and $600 \mathrm{mM}$. Table salt $(\mathrm{NaCl})$ was applied during soil mixing and pot filling, at the concentrations given by the following formula, in order to obtain the above referred levels of salinity:

NaCl required $\left(\mathrm{g} \mathrm{kg}^{-1}\right)=\frac{T S S \times 58.5 \times \text { Saturation }(\%)}{100 \times 1000}$

$\mathrm{TSS}=$ total soluble salts which were measured as: $\mathrm{TSS}=\left(\mathrm{EC}_{2}-\mathrm{EC}_{1}\right)$ $\times 10 ; \mathrm{EC}_{2}$ was required electrical conductivity, and $\mathrm{EC}_{1}$ was the $\mathrm{EC}$ in control soil. For the determination of saturation (\%), soil paste was prepared by the addition of distilled water, mixed and left for $2 \mathrm{~h}$ to reach equilibrium. The extract was obtained by filtering the saturated soil with filter paper; saturation was calculated by the following formula: 


$$
\text { Saturation }(\%)=\frac{\text { Loss in soil weight on drying }}{\text { Weight of soil after drying }} \times 100
$$

For plant nutrition, N, P, and $\mathrm{K}$ were applied as di-ammonium phosphate (1.87 $\mathrm{g} \mathrm{kg}^{-1}$ soil) and potash sulphate $\left(5.58 \mathrm{~g} \mathrm{~kg}^{-1}\right)$ prior to sowing. After 20 days from emergence, SA was foliar applied according to different treatments. Leaves were sprayed with a manual pump on both sides, using a constant volume on all pots; control pots were sprayed with water.

Fifteen days after SA treatments, plants were harvested and the following morphological, growth, physiological, enzymatic, hormonal and chemical traits were determined.

\section{Morphological and growth traits}

Three plants were selected from each pot to record their height, leaf number, root and shoot fresh weight and, following oven drying $\left(70^{\circ} \mathrm{C}\right)$, dry weight (DW).

\section{Leaf water status and pigments}

Relative water content (RWC) was determined according to Mostofa and Fujita (2013). The second top leaf was collected, weighed (FW), and then submerged in $\mathrm{dH}_{2} \mathrm{O}$ for $24 \mathrm{~h}$ in the dark. After excessive water was removed from the leaf sample, turgid weight (TW) was taken. Then, the samples were dried at $70^{\circ} \mathrm{C}$ to record DW. Based on these data, RWC was determined with the following equation:

$$
R W C(\%)=\frac{F W-D W}{T W-D W} \times 100
$$

Electrolyte leakage (EL) was determined by the method of Lutts et al. (1996). Fresh leaves were collected and washed with $\mathrm{dH}_{2} \mathrm{O}$ to remove any contamination. The leaf samples were placed in stoppered vials having $10 \mathrm{~mL} \mathrm{dH_{2 }} \mathrm{O}$ at $25^{\circ} \mathrm{C}$ on a rotary shaker. First electrical conductivity $\left(\mathrm{E}_{1}\right)$ was recorded after $24 \mathrm{~h}$; then the leaf samples were placed for $20 \mathrm{~m}$ in a water bath at $120^{\circ} \mathrm{C}$, cooled down to room temperature and second electrical conductivity $\left(\mathrm{E}_{2}\right)$ was measured. The final EL was calculated as:

$$
E L=\frac{E_{I}}{E_{2}} \times 100
$$

Chlorophyll $a, b$ and carotenoids were determined according to Arnon (1949). One g leaf samples were homogenized in $80 \%$ acetone; the extract was centrifuged, and the supernatant was used for recording the absorbance at $663,645,470 \mathrm{~nm}$ with a spectrophotometer (Hitachi U-2001, Tokyo, Japan), for the three respective pigments. Anthocyanin was assessed by the method of Kubo et al. (1999): $0.5 \mathrm{~g}$ plant sample was homogenized into $5 \mathrm{~mL}$ potassium phosphate buffer using pestle and mortar. The extract was centrifuged for $15 \mathrm{~min}$ and the absorbance was recorded at $535 \mathrm{~nm}$. A set of three replicates was used to determine the parameters related to leaf water status and photosynthetic pigments.

\section{Antioxidant enzymes and oxidative stress markers}

The catalase (CAT) content was determined according to $\mathrm{Fu}$ et al. (2017). Test tubes were prepared containing $100 \mu \mathrm{L}$ of $\mathrm{H}_{2} \mathrm{O}_{2}$ $(5.9 \mathrm{mM})+1000 \mu \mathrm{L}$ buffer and $100 \mu \mathrm{L}$ of plant extract. Absorbance was recorded at $240 \mathrm{~nm}$ with the aforementioned spectrophotometer, using an extinction coefficient of $39.4 \mathrm{mM}^{-1}$ $\mathrm{cm}^{-1}$.
The peroxidase (POD) content was measured according to Guan et al. (2009). The combination of reagents containing $100 \mu \mathrm{L}$ extract enzyme $+2700 \mu \mathrm{L}$ of $50 \mathrm{mM}$ potassium buffer $+100 \mu \mathrm{L}$ guaiacol and $100 \mu \mathrm{L} \mathrm{H}_{2} \mathrm{O}_{2}$ was used. A $0.5 \mathrm{~g}$ plant sample was homogenized with $5 \mathrm{ml}$ potassium phosphate buffer $(50 \mathrm{mM})$ having $\mathrm{pH} 7.0$ under ice-cold conditions and centrifuged at 15,000 $\mathrm{rpm}$. Thereafter, the absorbance was recorded at $470 \mathrm{~nm}$ using the aforementioned spectrophotometer.

The ascorbate peroxidase (APX) contents were determined by the methods of Nakano and Asada (1981). A mixture was prepared containing $100 \mu \mathrm{L}$ enzyme extracts, $100 \mu \mathrm{l}$ ascorbate $(7.5 \mathrm{mM})$, $100 \mu \mathrm{L} \mathrm{H}_{2} \mathrm{O}_{2}(300 \mathrm{mM})$, and $2.7 \mathrm{~mL}$ potassium buffer $(25 \mathrm{mM})$. Thereafter, the absorbance was recorded at $290 \mathrm{~nm}$ with the aforementioned spectrophotometer, using an extinction coefficient of $2.8 \mathrm{mM}^{-1} \mathrm{~cm}^{-1}$.

Ascorbic acid was determined according to Mukherjee and Chouduri (1983). Leaf samples $(0.5 \mathrm{~g})$ were standardized with 5 $\mathrm{mL}$ of $10 \%$ trichloroacetic acid solution, and centrifuged for 10 $\mathrm{min}$ at $8000 \mathrm{rpm}$. After centrifugation, $0.5 \mathrm{ml}$ of dithiocarbamate reagent was added to $2 \mathrm{ml}$ supernatant, incubated for $3 \mathrm{~h}$ at $37^{\circ} \mathrm{C}$, cooled rapidly by ice-cooling for about 10 minutes, and then $2 \mathrm{~mL}$ sulfuric acid was added dropwise and shaken lightly. The mixture was kept for $30 \mathrm{~min}$ at $30^{\circ} \mathrm{C}$, then absorbance was recorded at 520 $\mathrm{nm}$ with the aforementioned spectrophotometer, determining ascorbic acid content based on standard curves produced from samples with known concentrations.

The $\mathrm{H}_{2} \mathrm{O}_{2}$ content was assessed according to Velikova et al. (2000). A 0.5 g plant sample was ground in $5 \mathrm{ml}$ of trichloroacetic acid and centrifuged. Afterward, $1 \mathrm{~mL}$ extract was placed in a test tube with $166 \mathrm{mg}$ of $1 \mathrm{M}$ potassium iodide and $100 \mu \mathrm{L}$ potassium phosphate buffer for 30 minutes. The absorbance was then read at $390 \mathrm{~nm}$ with the aforementioned spectrophotometer, using an extinction coefficient of $0.28 \mu \mathrm{M}^{-1} \mathrm{~cm}^{-1}$.

Malondialdehyde (MDA) was determined according to Rao and Sresty (2000). Plant samples $(0.5 \mathrm{~g})$ were ground with $5 \mathrm{~mL}$ trichloroacetic acid, and samples were centrifuged for $15 \mathrm{~m}$ at $12,000 \mathrm{rpm}$ at $4^{\circ} \mathrm{C}$. The mixture containing $1 \mathrm{~mL}$ plant sample and $1 \mathrm{ml}$ of thiobarbituric acid was heated for 30 minutes at $100^{\circ} \mathrm{C}$, and cooled rapidly in ice bath at $4^{\circ} \mathrm{C}$. The MDA concentration was determined at $532 \mathrm{~nm}$ and $600 \mathrm{~nm}$ with the aforementioned spectrophotometer, using an extinction coefficient of $1.53 \mathrm{mM}^{-1} \mathrm{~cm}^{-1}$. The mean value of aforementioned parameters was calculated from a set of three replicates.

\section{Osmo-regulating compounds and hormones}

Free amino acids were assessed through the procedure of Hamilton and Van Slyke (1943). Leaf samples (0.5 g) were ground with $5 \mathrm{~mL}$ phosphate buffer $(\mathrm{pH} 7.8)$ and centrifuged at 15,000 rpm for 15 minutes. One $\mathrm{ml}$ extract was placed in a test tube containing $1 \mathrm{~mL}$ of ninhydrin and pyridine and left in a water bath for 30 minutes at $90^{\circ} \mathrm{C}$. Then, $\mathrm{dH}_{2} \mathrm{O}$ was added to a volume of $25 \mathrm{~mL}$, and absorbance was read at $570 \mathrm{~nm}$ with the aforementioned spectrophotometer, determining free amino acid content based on standard curves produced from samples with known concentrations.

Total soluble proteins were determined with the Bradford (1976) method. Leaf samples $(0.5 \mathrm{~g})$ were ground in $5 \mathrm{~mL}$ phosphate buffer ( $\mathrm{pH} 7.8$ ) and centrifuged for 15 minutes at 15,000 rpm at $4^{\circ} \mathrm{C}$. Thereafter, $1 \mathrm{~mL}$ extract was transferred into test tubes, 3 $\mathrm{mL}$ Bradford reagent was added and the mixture was left at room temperature for 15 minutes prior to reading the absorbance at 595 $\mathrm{nm}$ using the aforementioned spectrophotometer. The concentration of total soluble proteins was determined using standard curves derived from samples with known concentrations.

Total soluble sugars were measured by placing 1-2 drops of 
supernatant on the prism of a digital refractometer, reading the Brix percent value.

The proline content was measured by the procedures of Bates et al. (1973). Plant samples $(0.5 \mathrm{~g})$ were extracted with $10 \mathrm{ml}$ of $3 \%$ sulpho-salicylic acid and centrifuged for 10 minutes at 10,000 $\mathrm{rpm}$. The supernatant was supplied with acid-ninhydrin and placed in a water bath for 30 minutes at $90^{\circ} \mathrm{C}$. Then, absorbance was read at $520 \mathrm{~nm}$ with the aforementioned spectrophotometer, determining proline content based on standard curves produced from samples with known concentrations.

Plant hormones, IAA and ABA were determined on $0.5 \mathrm{~g}$ samples ground in $2 \mathrm{~mL} 80 \%$ methanol with $40 \mathrm{mg}$ butylated hydroxytoluene. Samples were incubated for $48 \mathrm{~h}$ at $4^{\circ} \mathrm{C}$, and were centrifuged for 15 minutes at $1900 \times \mathrm{g}$. Afterwards, the C18 Sep-Pak cartridges were used to pass the supernatant followed by the use of $10 \mathrm{~mL}$ pure ethanol, and then $10 \mathrm{~mL}$ of ether to determine hormonal fractions which were $\mathrm{N}_{2}$ dried at $20^{\circ} \mathrm{C}$. The extract was subsequently dissolved in $0.1 \%$ gelatin ( $\mathrm{pH} 7.5$ ), and 0.1 Tween-20 containing $2 \mathrm{~mL}$ of phosphate-buffered saline. Lastly, the IAA and ABA concentrations were determined following the protocols of Weiler et al. (1981).

The GA concentration was determined following the protocols of Berríos et al. (2004). The extraction of plant samples $(0.1 \mathrm{~g})$ was done by using $3 \mathrm{~mL} 96 \%$ ethanol. Extract absorbance was read at $254 \mathrm{~nm}$ with the aforementioned spectrophotometer, and GA contents were determined with a linear regression equation.

The ethylene evolution was measured using the protocols of Sun et al. (2007 and 2010). Samples were excised from the plant, and were placed in vials for 30 minutes before sealing. Then samples were incubated for $2 \mathrm{~h}$ at room temperature, and $1 \mathrm{~mL}$ of gas sample was taken with a syringe from the headspace. The concentration of ethylene was measured using a gas chromatograph fitted with flame ionization detector and a capillary column (Porapak Q 80-100). The mean value of each osmo-regulating compound and hormone was determined by using three replicates.

\section{Ion accumulation}

Samples of the three plant organs (roots, stem and leaves) were collected, washed with $\mathrm{dH}_{2} \mathrm{O}$, dried at $65^{\circ} \mathrm{C}$, and milled to make powder. The powdered samples $(0.5 \mathrm{~g})$ were digested with $1: 2 \mathrm{HCl}$ and $\mathrm{HNO}_{3}$ for 10 minutes at $180^{\circ} \mathrm{C}$, filtered and diluted with $\mathrm{dH}_{2} \mathrm{O}$ (Hsu and Kao, 2003). The acid mixture containing $\mathrm{dH}_{2} \mathrm{O}$ was used to measure the element $\left(\mathrm{Na}^{+}, \mathrm{K}^{+}, \mathrm{Ca}^{2+}\right.$ and $\left.\mathrm{Mg}^{2+}\right)$ concentration in plant organs by flame photometer (Jenway PFP-7, Burlington, NJ, USA). For $\mathrm{Cl}^{-}$determination, samples of the three organs were extracted in distilled water and $\mathrm{Cl}^{-}$concentration was determined by a chloride analyser (model 926, Sherwood Scientific, Cambridge, UK). A set of three replicates was used to determine the mean value of each ion.

\section{Experimental design and data analysis}

The experiment was arranged in a completely randomized factorial design with three replicates. Data from all traits were submitted to a two-way ANOVA for salinity, SA and their interaction. Tukey's HSD test at $\mathrm{P} \leq 0.05$ was used to separate levels in significant ANOVA sources. Four of the nine treatments resulting from the salinity $\times$ SA combination, excluding the intermediate level of salinity $(300 \mathrm{mM})$ and $\mathrm{SA}\left(6 \mathrm{dS} \mathrm{m} \mathrm{m}^{-1}\right)$, were more specifically focused in this work (Table 1), and submitted to one-way ANOVA for specific traits (element concentrations, contents and TIs). Data from all treatments and the complete two-way ANOVA are reported as Supplementary Materials in the online Appendix.

A principal component analysis (PCA) was performed on data of all traits from the four selected treatments. In the PCA, the prin- cipal components (PCs) were obtained from centred and scaled quantitative variables, through diagonalization of the correlation matrix and extraction of the associated eigenvectors and eigenvalues. In the PCA, the main traits (shoot DW, root DW, R:S, RWC, EL, total chlorophyll, carotenoids, antocyanin, POD, CAT, APX, vitamin $\mathrm{C}, \mathrm{H}_{2} \mathrm{O}_{2}$, MDA, free amino acids, soluble proteins, soluble sugars, proline, IAA, GA, ABA, ethylene, $\mathrm{Na}, \mathrm{K}, \mathrm{Ca}, \mathrm{Mg}$ and $\mathrm{Cl}$ concentration in the whole plant) were set as active quantitative variables, while the selected Salinity levels $\left(0\right.$ and $\left.12 \mathrm{dS} \mathrm{m}^{-1}\right)$ and SA levels ( 0 and $600 \mathrm{mM}$ ) were used as supplementary categorical variables.

Statistics was performed with the R 6.3.6 statistical software, using the Car (Fox et al., 2018) and Emmeans (Lenth et al., 2020) packages for the ANOVA and post-hoc test, and the FactoMineR package (Lê et al., 2008) for PCA. Charts were created with the ggplot2 (Wickham, 2009) R package.

\section{Results}

\section{Morphological and growth traits}

Soil salinity determined a relevant reduction in maize growth and DW. Under no SA addition (Figure 1), the strongest salinity (Sal.12/SA0) resulted in approximately $-20 \%$ plant height and leaf number, $-35 \%$ leaf DW, $-25 \%$ stem DW, $-30 \%$ shoot DW, $-15 \%$ root DW and $+15 \% \mathrm{R}: \mathrm{S}$, with respect to the control (Sal.0/SA0). Addition of SA determined a slight improvement of all growth traits under no salinity (Sal.0/SA600 vs Sal.0/SA0), and a stronger improvement under salinity (Sal.12/SA600 vs Sal.12/SA0). In the latter case, shoot DW attained approximately $-15 \%$ compared to the control; i.e., it closed about half of the gap determined by salinity without SA addition. In the complete data set (Table S1 in the Supplementary Materials), salinity and SA exhibited significant interactions in plant height, stem DW and shoot DW. In these interactions, SA always mitigated salinity negative effects, in agreement with the two single factors' effects.

\section{Leaf water status and pigments}

Salinity altered leaf water status, as shown by ca. $-30 \%$ RWC and $+40 \%$ EL with Sal.12/SA0 vs the control (Figure 2). The four pigments were curbed by salinity (Figure 2), staging variations from ca. $-20 \%$ (chlorophyll $a$ ) to almost $-60 \%$ (chlorophyll $b$ ).

Table 1. Scheme of the nine treatments resulting from the combination of three levels of soil salinity with three levels of salicylic acid supplied to maize. Shaded rows indicate the four treatments more closely addressed in this paper; they are abbreviated as it appears in the subsequent tables and figures.

\begin{tabular}{lccc}
$\begin{array}{l}\text { Treatment } \\
\text { no. }\end{array}$ & $\begin{array}{c}\text { Salinity } \\
\left(\mathrm{dS} \mathrm{m}^{-1}\right)\end{array}$ & $\begin{array}{c}\text { Salicylic acid } \\
(\mathrm{mM})\end{array}$ & $\begin{array}{c}\text { Abbreviation } \\
1\end{array}$ \\
\hline & 0 & 0 & Sal.0/SA0 \\
\hline 2 & 0 & 300 & \\
3 & 0 & 600 & Sal.0/SA600 \\
\hline 4 & 6 & 0 & \\
5 & 6 & 300 & \\
6 & 6 & 600 & Sal.12/SA0 \\
\hline 7 & 12 & 0 & \\
\hline 8 & 12 & 300 & Sal.12/SA600 \\
\hline 9
\end{tabular}


Addition of SA determined a slight improvement of all traits under no salinity (Sal.0/SA600 vs Sal.0/SA0), and a noticeable recovery under salinity (Sal.12/SA600 vs Sal.12/SA0). In the complete data set (Table S2 in the Supplementary Materials), significant salinity $\times$ SA interactions were observed in RWC, EL and anthocyanin. In these interactions, SA still tended to mitigate salinity negative effects. It is perceived, across the six traits reported in Table S2, that the high dosage of SA $(600 \mathrm{mM})$ was able to offset the negative effects of the intermediate level of salinity $\left(6 \mathrm{dS} \mathrm{m}^{-1}\right)$; not those of the highest salinity $\left(12 \mathrm{dS} \mathrm{m}^{-1}\right)$.

\section{Antioxidant enzymes and oxidative stress markers}

The four antioxidant enzymes (POD, CAT, APX and vitamin C) and the two oxidative stress markers $\left(\mathrm{H}_{2} \mathrm{O}_{2}\right.$ and MDA) responded to salinity (Sal.12/SA0) with increases from a minimum of ca. $+10 \%$ (MDA) to a maximum of $+140 \%$ (APX) vs the control (Figure 3). Under no salinity with addition of SA, two antioxidant enzymes (POD and vitamin C) were remarkably increased; the other two antioxidant enzymes (CAT and APX) were less strongly increased, while the two oxidative stress markers were slightly reduced. Under salinity, addition of SA determined further increases in the four antioxidant enzymes (Sal.12/SA600 vs Sal.12/SA0), whereas the two oxidative stress markers were slightly reduced. In the complete data set (Table S3 in the Supplementary Materials), all traits except $\mathrm{H}_{2} \mathrm{O}_{2}$ staged significant salinity $\times$ SA interactions. As a result, the four antioxidant enzymes were doubly enhanced by salinity and SA; thus, the low initial values under control conditions increased in parallel with salinity and SA levels. Conversely, in the case of the two oxidative stress markers, SA mitigated salinity effects. As a result, the high SA level under intermediate salinity (Sal.6/SA600) was able to restore $\mathrm{H}_{2} \mathrm{O}_{2}$ and MDA values similar to the control (Sal.0/SA0).

\section{Osmo-regulating compounds and hormones}

Salinity determined variable effects on osmo-regulating compounds and hormones (Figure 4): free amino-acids, soluble proteins and GA were reduced (variations between ca. $-20 \%$ and $40 \%$ ), while soluble sugars, proline, IAA, ABA and ethylene were increased (from approximately $+20 \%$ to $+140 \%$ ). Under no salinity, SA addition increased to a variable extent all traits except ABA and ethylene that were decreased. Under salinity, addition of SA determined stronger variation in soluble sugars, proline and IAA (Sal.12/SA600 vs Sal.12/SA0), while in the other five traits milder variations were observed. In the complete data set (Table S4 in the

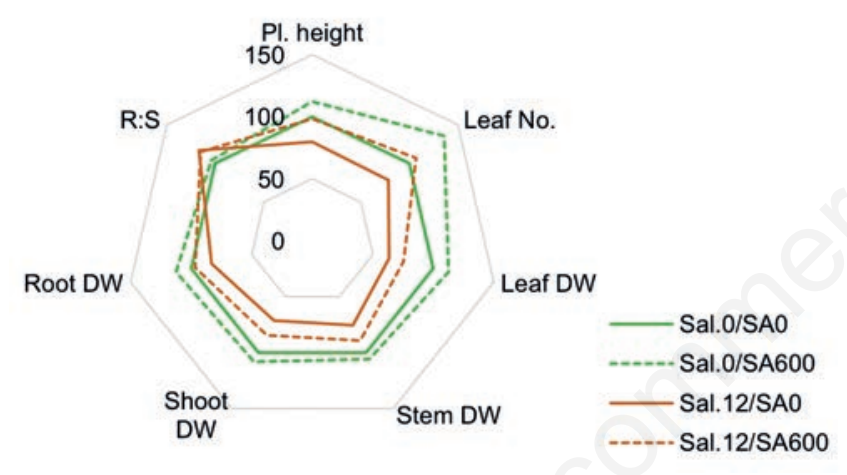

Figure 1. Morphological and growth traits in the four selected treatments, based on relative data $(S a l .0 / S A 0=100)$. Salinity and salicylic acid (SA) treatments are fully described in Table 1. DW, dry weight; R:S, root to shoot ratio.
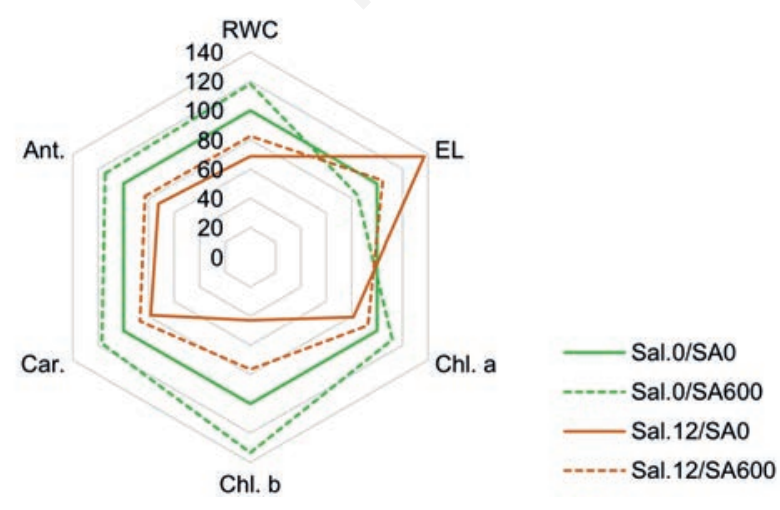

Figure 2. Leaf water status and pigments in the four selected treatments, based on relative data $(\mathrm{Sal.0/SA0}=100)$. Salinity and salicylic acid (SA) treatments are fully described in Table 1. RWC, relative water content; EL, electrolyte leakage; Chl. a and b, chlorophyll a and b, respectively; Car., carotenoids; Ant., anthocyanin.

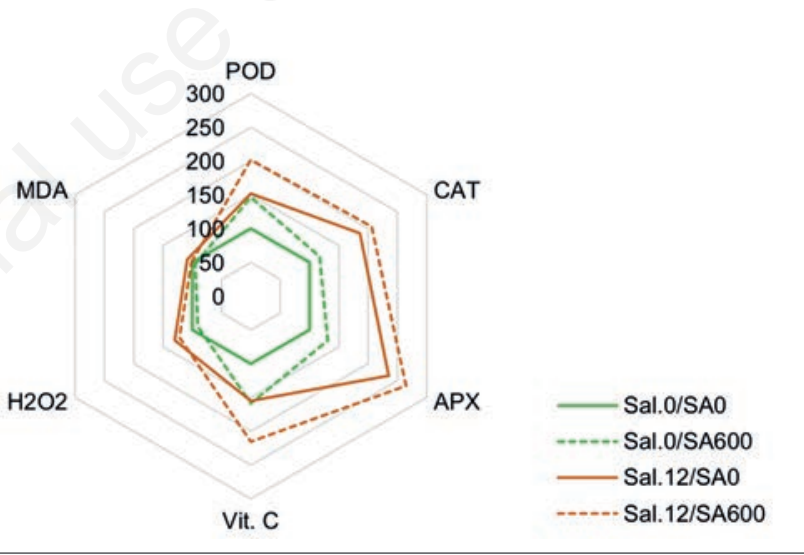

Figure 3. Antioxidant enzymes and oxidative stress markers in the four selected treatments, based on relative data $(S a l .0 / S A 0=100)$. Salinity and salicylic acid (SA) treatments are fully described in Table 1. POD, peroxidase; CAT, catalase; APX, ascorbate peroxidase; MDA, malondialdehyde.

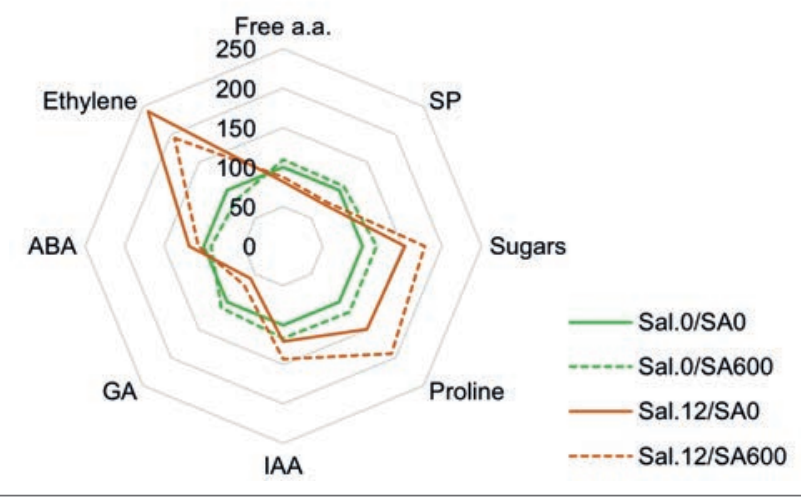

Figure 4. Osmo-regulating compounds and hormones in the four selected treatments, based on relative data $($ Sal.0/SA0 $=100)$. Salinity and salicylic acid (SA) treatments are fully described in Table 1. Free a.a., free amino acids; SP, soluble proteins; IAA; indole-3-acetic acid; GA, gibberellic acid; ABA, abscisic acid. 
Supplementary Materials), free amino-acids, soluble proteins, soluble sugars and ethylene exhibited significant salinity $\times$ SA interactions. SA mitigated salinity effects in free amino-acids, soluble proteins, GA, ABA and ethylene; in the first four traits, high SA level under intermediate salinity (Sal.6/SA600) was able to restore values quite similar to the control (Sal.0/SA0), whereas in the last trait (ethylene) this effect was far from being achieved.

\section{Element accumulation and translocation to plant organs}

The concentration of the four investigated cations $(\mathrm{Na}, \mathrm{K}, \mathrm{Ca}$ and $\mathrm{Mg}$ ) and the anion $(\mathrm{Cl})$ in plant organs is reported in the Tables S5 and S6 in the Supplementary Materials. The element concentration and content in the whole plant, referred to the four selected treatments (Table 2), indicate that salinity determined sharp increases in $\mathrm{Na}$ and $\mathrm{Cl}$ concentration, in exchange for decreases in $\mathrm{K}, \mathrm{Ca}$ and $\mathrm{Mg}$. This reflected in strong increases in $\mathrm{Na}$ and $\mathrm{Cl}$ content under salinity, despite plant DW reduction. Conversely, $\mathrm{K}, \mathrm{Ca}$ and $\mathrm{Mg}$ content decreased under salinity, as the combined effect of lower element concentrations and lower plant DW.

With SA addition, $\mathrm{Na}$ and $\mathrm{Cl}$ concentration and content were reduced under both no salinity and salinity, while $\mathrm{K}, \mathrm{Ca}$ and $\mathrm{Mg}$ concentration and content were enhanced under both no salinity and salinity (Table 2).

The allocation of the above described element contents across the three plant organs is expressed by the TI (Figure 5). In the case of $\mathrm{Na}$ (Figure 5A), a higher proportion of the element remained in the roots or was translocated to the stem under salinity (Sal.12/SA0 and Sal.12/SA600). Conversely, SA determined the allocation of a higher proportion of $\mathrm{Na}$ to leaves under no salinity (Sal.0/SA600).

In the case of $\mathrm{K}$ (Figure 5B), a higher proportion of the element was withheld at root level under salinity (Sal.12/SA0 and Sal.12/SA600), whereas a higher proportion was translocated to the stem under no salinity (Sal.0/SA0 and Sal.0/SA600). In both cases, SA addition did not play a significant role in the allocation to different organs.

In the case of $\mathrm{Ca}$ (Figure 5C), a higher proportion of the element was withheld at root level under salinity (Sal.12/SA0 and Sal.12/SA600), whereas a higher proportion was translocated to the leaves under no salinity (Sal.0/SA0 and Sal.0/SA600). SA addition did not play a significant role in the allocation to different organs for $\mathrm{Ca}$.

In the case of $\mathrm{Mg}$ (Figure 5D), salinity and SA addition did not affect the element allocation to roots and stem. At the leaf level, instead, a slightly higher element translocation was observed under salinity (Sal.12/SA0) vs no salinity and SA addition (Sal.0/SA600).

Lastly (Figure 5D), a higher proportion of $\mathrm{Cl}$ was withheld at root level under salinity (Sal.12/SA0 and Sal.12/SA600), as for the cations $\mathrm{Na}, \mathrm{K}$ and $\mathrm{Ca}$. Under no salinity (Sal.0/SA0 and Sal.0/SA600), a higher proportion was translocated to the stem. SA

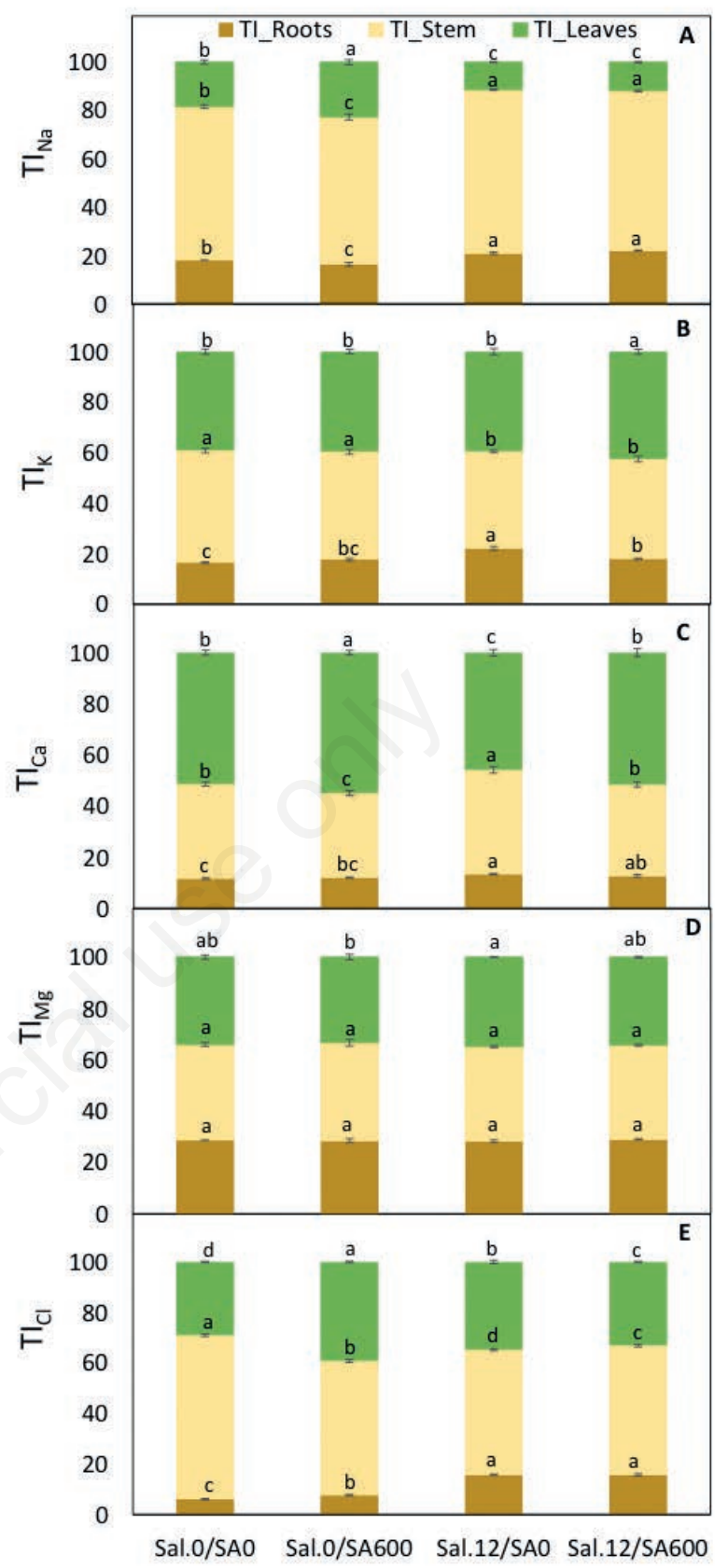

Figure 5. Translocation Index (TI) of (A) sodium, (B) potassium, (C) calcium, (D) magnesium and (E) chloride to plant organs. Salinity and salicylic acid (SA) treatments are fully described in Table 1. Vertical bars, $\pm S E(n=3)$. Different letters indicate significant differences for the same organ (Tukey test at $\mathrm{P} \leq 0.05$ ).

Table 2. Element concentration and content in the whole plant of maize at different levels of salinity and salicylic acid.

\begin{tabular}{|c|c|c|c|c|c|c|c|c|c|c|c|}
\hline \multirow{2}{*}{ Treatment } & $\mathrm{Na}$ & K & $\mathrm{Ca}$ & Mg & $\mathrm{Cl}$ & \multirow{2}{*}{$\begin{array}{l}\text { Plant DW } \\
\left(\text { g plant }^{-1}\right)\end{array}$} & \multirow{2}{*}{\multicolumn{5}{|c|}{$\left.{ }_{(\mathrm{mg} \text { plant }}{ }^{-1}\right)^{\mathrm{Mg}}$}} \\
\hline & \multicolumn{5}{|c|}{$\left(\mathrm{mg} \mathrm{g} \mathrm{g}^{-1} \mathrm{DW}\right)$} & & & & & & \\
\hline Sal.0/SA0 & $3.2^{\mathrm{c}}$ & $24.5^{\mathrm{b}}$ & $77.4^{\mathrm{b}}$ & $62.2^{\mathrm{b}}$ & $4.1^{\mathrm{c}}$ & $6.36^{\mathrm{b}}$ & $20.2^{b}$ & $156.3^{b}$ & $492.0^{\mathrm{b}}$ & $394.9^{b}$ & $26.7^{\mathrm{b}}$ \\
\hline Sal.0/SA600 & $2.1^{\mathrm{d}}$ & $27.2^{\mathrm{a}}$ & $88.5^{\mathrm{a}}$ & $70.0^{\mathrm{a}}$ & $2.5^{\mathrm{d}}$ & $6.94^{\mathrm{a}}$ & $14.8^{c}$ & $189.6^{\mathrm{a}}$ & $613.8^{\mathrm{a}}$ & $485.2^{\mathrm{a}}$ & $17.1^{\mathrm{c}}$ \\
\hline Sal.12/SA0 & $20.5^{\mathrm{a}}$ & $13.5^{\mathrm{d}}$ & $51.9 \mathrm{~d}$ & $41.6^{\mathrm{d}}$ & $35.3^{\mathrm{a}}$ & $4.71^{\mathrm{d}}$ & $96.8^{\mathrm{a}}$ & $64.3^{\mathrm{d}}$ & $245.3^{d}$ & $195.9^{d}$ & $167.0^{\mathrm{a}}$ \\
\hline Sal.12/SA600 & $17.1^{\mathrm{b}}$ & $17.6^{\mathrm{c}}$ & $66.5 \mathrm{c}$ & $50.1^{\mathrm{c}}$ & $30.1^{\mathrm{b}}$ & $5.55^{\mathrm{c}}$ & $95.1^{\mathrm{a}}$ & $98.4^{c}$ & $369.6^{c}$ & $277.8^{c}$ & $167.8^{\mathrm{a}}$ \\
\hline $\mathrm{P}$ & $<0.001^{* *}$ & $<0.001^{* *}$ & $<0.001^{* *}$ & $<0.001^{* *}$ & $<0.001^{* *}$ & $<0.001^{* *}$ & $<0.001^{* *}$ & $<0.001^{* *}$ & $<0.001^{* *}$ & $<0.001^{* *}$ & $<0.001^{* *}$ \\
\hline
\end{tabular}

Salinity and salicylic acid (SA) treatments are fully described in Table 1. DW, dry weight; n.s. and **indicate non-significant and significant at $P \leq 0.01$, respectively. Different letters indicate statistical differences (Tukey test at $\mathrm{P} \leq 0.05$ ). 
addition appears to have favoured $\mathrm{Cl}$ allocation to leaves under no salinity (Sal.0/SA600); to have contrasted it under salinity (Sal.12/SA600).

\section{Principal component analysis}

The first two PCs were retained for PCA interpretation; they explained $82.3 \%$ and $15.6 \%$ of the total variance, respectively, and featured the respective eigenvalues of 22.23 and 4.22 . The correlation coefficients between the quantitative (plant traits) and qualitative (salinity and SA levels) variables, on one side, and the first two PCs, o the other side, are reported in Table 3, and graphically represented in the Supplementary Materials (Figure S1).

In the biplot of quantitative and qualitative variables (Figure 6 ), the quantitative variables (green circles) whose values increased under salinity were grouped on the positive side of PC1, i.e., they were shown to be positively related to PC1 (Table 3). They included total $\mathrm{Na}$ and $\mathrm{Cl}$ concentration, antioxidant enzymes (vitamin C, APX, CAT, POD), oxidative stress markers (MDA and $\mathrm{H}_{2} \mathrm{O}_{2}$ ), some osmo-regulating compounds (proline and free sugars), and some hormones as ABA, IAA and ethylene. Not surprisingly, the root to shoot ratio was also placed on this side of PC1.

In exchange for this, the quantitative variables whose values decreased under salinity were grouped on the negative side of PC1, i.e., they were shown to be negatively related to PC1. They included shoot and root dry weight, total $\mathrm{Ca}, \mathrm{K}$ and $\mathrm{Mg}$ concentration, all pigments (chlorophyll a $+b$, carotenoids, anthocyanin), leaf RWC, soluble proteins, free amino acids, and GA.

The few quantitative variables positively related to PC2 (Table 3) were IAA, POD, proline and vitamin $\mathrm{C}$, which were, therefore, grouped on the positive side of PC2 (Figure 6). No quantitative variable was negatively related to $\mathrm{PC} 2$, meaning that none of the

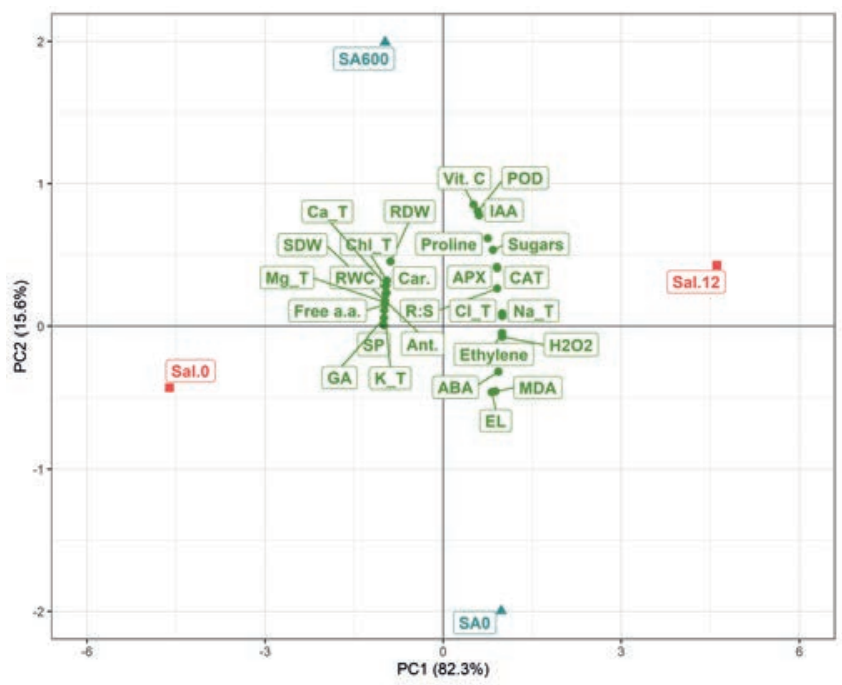

Figure 6. PCA biplot of variables. Green circles indicate the barycenters of the measured traits, blue triangles indicate the barycenters of the salicylic acid treatments $(S A ; 0$ and $600 \mathrm{mM})$, red squares indicate the barycenters of the salinity treatments (Sal.; 0 and $12 \mathrm{dS} \mathrm{m}^{-1}$ ). ABA, abscisic acid; Ant., antocyan; APX, ascorbate peroxidase; $\mathrm{Ca} \_\mathrm{T}$, total (i.e., whole plant) $\mathrm{Ca}$ concentration; Car., carotenoids; CAT, catalase; Chl_T, total (i.e., a + b) chlorophyll content; $\mathrm{Cl}_{-} \mathrm{T}$, total $\mathrm{Cl}$ concentration; $\mathrm{EL}$, electrolyte leakage; Free a.a., free amino acids; GA, gibberellic acid; IAA, indole-3-acetic acid; $K_{-}$T, total $\mathrm{K}$ concentration; $\mathrm{Mg}_{-} \mathrm{T}$, total $\mathrm{Mg}$ concentration; MDA, malondialdehyde; $\mathrm{Na}$ - $\mathrm{T}$, total $\mathrm{Na}$ concentration; POD, peroxidase; R:S, root to shoot; RDW, root dry weight; RWC, relative water content; SDW, shoot sry weight; SP, soluble proteins.

Table 3. Correlation coefficients between quantitative and qualitative variables, and the first two principal components.

\begin{tabular}{|c|c|c|c|c|c|}
\hline & & & variable & & \\
\hline & PC1 & PC2 & & PCl & PC2 \\
\hline $\mathrm{ABA}$ & $0.93^{* *}$ & $-0.32^{\mathrm{ns}}$ & K_T & $-0.98 * *$ & $0.16^{\mathrm{ns}}$ \\
\hline Antocyanin & $-0.98^{* *}$ & $0.18^{\mathrm{ns}}$ & MDA & $0.88^{* *}$ & $-0.46^{\text {ns }}$ \\
\hline APX & $0.91^{* *}$ & $0.41^{\mathrm{ns}}$ & Mg_T & $-0.97 * *$ & $0.60^{\mathrm{ns}}$ \\
\hline Ca_T & $-0.93^{* *}$ & $0.36^{\mathrm{ns}}$ & Na_T & $1^{* *}$ & $0.07^{\mathrm{ns}}$ \\
\hline Carotenoids & $-0.95^{* *}$ & $0.24^{\mathrm{ns}}$ & POD & $0.59^{*}$ & $0.80 * *$ \\
\hline CAT & $0.91^{* *}$ & 0.40ns & Proline & $0.75^{* *}$ & $0.61^{*}$ \\
\hline Chl_T & $-0.94 * *$ & $0.32 \mathrm{~ns}$ & $\mathrm{R}: \mathrm{S}$ & $0.91^{* *}$ & $0.26^{\mathrm{ns}}$ \\
\hline Cl_T & $0.99 * *$ & $0.08^{\text {ns }}$ & RDW & $-0.88^{* *}$ & $0.46^{\mathrm{ns}}$ \\
\hline EL & $0.82^{* *}$ & $-0.46^{\mathrm{ns}}$ & RWC & $-0.97 * *$ & $0.23^{\mathrm{ns}}$ \\
\hline Ethylene & $0.99 * *$ & $-0.05^{\text {ns }}$ & SDW & $-0.98^{* *}$ & $0.18^{\text {ns }}$ \\
\hline Free a.a. & $-0.98^{* *}$ & $0.15^{\mathrm{ns}}$ & SP & $-1^{* *}$ & $0.01^{\mathrm{ns}}$ \\
\hline GA & $-0.99 * *$ & $0.06^{\mathrm{ns}}$ & Sugars & $0.84^{* *}$ & $0.53^{\mathrm{ns}}$ \\
\hline $\mathrm{H}_{2} \mathrm{O}_{2}$ & $0.99 * *$ & $-0.07^{\mathrm{ns}}$ & Vit. C & $0.52^{\mathrm{ns}}$ & $0.85^{* *}$ \\
\hline IAA & $0.61^{*}$ & $0.78^{* *}$ & & & \\
\hline & $\begin{array}{l}\text { Cate } \\
\text { PCl }\end{array}$ & $\begin{array}{l}\text { les } \\
\text { PC2 }\end{array}$ & & & \\
\hline $\mathrm{NaCl}$ & $0.96^{* *}$ & $0.04^{\mathrm{ns}}$ & & & \\
\hline SA & $0.04^{\mathrm{ns}}$ & $0.94^{* *}$ & & & \\
\hline
\end{tabular}


surveyed traits was significantly affected by SA.

Of the two qualitative, alias categorical, variables, salinity (red squares) was strongly aligned with PC1 (Figure 6): the high level (Sal. $12 \mathrm{dS} \mathrm{m}^{-1}$ ) was far away on the positive side mirroring the null level (Sal. 0) far away on the negative side. Conversely, SA (cyan triangles) was strongly aligned with PC2 (Figure 6): the high level (SA $600 \mathrm{mM}$ ) was far away on the positive side mirroring the untreated (SA 0 ) on the negative side.

Hence, it can be inferred that the first $\mathrm{PC}$ represents the salinity effects, while the second PC the SA effects.

\section{Discussion}

Salt stress diminishes plant growth since the early stages, due to oxidative damage, ionic and osmotic stress, and hormonal imbalances (Sarkar et al., 2018). Plant response to salinity depends on the degree of specific tolerance and phenotypic plasticity to environmental features (Al-Whaibi et al., 2012). Exogenous SA application has proved able to improve plant adaptation to salinity and reduce its impact on growth (Kudla et al., 2018; Waqas et al., 2019). Our results are consistent with the above findings reported in the literature, and provide further clues to the interpretation of plant behaviour under the contrasting influence of a stressor as salinity, and a mitigating agent as SA.

The beneficial effects of exogenous SA application at the seedling/early growth stages have already been reported in various plant species (Shakirova et al., 2003; Li et al., 2014; Ahmed et al., 2020), including maize (Hussein et al., 2007; Fahad and Bano, 2012). It is generally agreed that initial plant stages are those most sensitive to salt stress (Rhoades et al., 1992; Munns, 2002; Parida and Das, 2005), resulting in growth impairments and physiological damages that can hardly be recovered in the rest of plant life.

The improvement of leaf pigments, namely chlorophyll $a$ and $b$, through foliar applied SA (Figure 2) is the premise for sustained photosynthesis under adverse conditions (Li et al., 2014).

The RWC reduction incurred by salinity is also well documented in the literature (Parida and Das, 2005; Karlidag et al., 2009). Supplying SA can mitigate this effect to a large extent (Figure 2), as documented in maize (Escobar et al., 2010) and other plants as barley and cucumber (El-Tayeb, 2005; Yildirim et al., 2008), where SA benefit is attributed to lower transpiration rates associated with higher leaf diffuse resistance.

The EL determined by damaged cellular membrane under salinity was also mitigated by SA (Figure 2), in agreement with previous studies (Parida and Das, 2005; Yildirim et al., 2008). Maintenance of membrane integrity plays a major role against salt stress (Stevens et al., 2006). The EL reduction obtained with SA supply is due to enhanced activity of anti-oxidant enzymes and increased $\mathrm{Ca}$ uptake, leading to higher membrane integrity (ElTayeb, 2005; Fahad and Bano, 2012).

The anti-oxidant enzymes augmenting under stress conditions, were further enhanced by SA (Figure 3). It is evidenced that SA application acts as cell protectant alleviating the effects of the oxidative stress by increasing cell anti-oxidant activity (Sharma, 2013; Khan et al., 2012), which is responsible for scavenging the reactive oxygen species (ROS) created by the oxidative stress, and for reducing the EL determined by loss of membrane integrity (Faried et al., 2017). Therefore, the decrease of the two oxidative stress markers $\left(\mathrm{H}_{2} \mathrm{O}_{2}\right.$ and MDA), is consistent with the increase of the investigated anti-oxidant enzymes (i.e., POD, CAT, APX and vitamin C) (Figure 3). Additionally, SA has a binding affinity with CAT, the anti-oxidant enzyme involved in ROS metabolism and redox homeostasis, resulting in increased salt tolerance (Hayat et al., 2008; Fahad and Bano, 2012; Sharma, 2013).

Salinity exerted a variable effect on osmo-regulating compounds: free amino acids and soluble proteins were depressed, while soluble sugars and proline were enhanced (Figure 4). However, they were all enhanced by SA under both saline and nonsaline conditions. The increase in free amino acids with SA supply is consistent with previous findings in wheat (Hamid et al., 2010). In general, a higher level of free amino acids creates a gradient of osmotic potential facilitating the inward movement of water to prevent the effect of salt stress (El-Saidi, 1997).

The increase in soluble proteins is possibly due to SA induced protein kinase synthesis and higher nitrate reductase activity. This is associated with a better regulation of various metabolic processes including cell division and differentiation, thanks to enhanced anti-oxidant activities (El-Tayab, 2005; Fahad and Bano, 2012).

Increased synthesis of soluble sugars, as way to improve salt tolerance in maize (Fahad and Bano, 2012), in our experiment appeared to be triggered both by salinity and SA application (Figure 4).

Proline, a non-polar amino acid, was also enhanced both by salinity and SA supply (Figure 4). SA favours the metabolic pathways and transduction signalling that up-regulate the biosynthesis of proline, which is necessary to maintain ionic homeostasis and low cytosolic potential (Faried et al., 2017). Therefore, the increase in proline by SA application improves the osmotic adjustment and plant defences by activating membrane stability, osmotic regulation, ROS scavenging, protein and enzymatic activities (Fahad and Bano, 2012), which all result in improved photosynthesis and overall plant production (Eraslan et al., 2007).

In our experiment, plant hormones were variably influenced by salinity and SA (Figure 4). The role of IAA in salinity tolerance is ambiguous in the literature, and changes in IAA synthesis and metabolism under salinity need to be better elucidated. However, the IAA increase under salinity is consistent with previous studies (Fahad and Bano, 2012; Shaki et al., 2019). Additionally, since IAA improves cell wall extensibility, the role of SA may be to sustain cell growth under reduced hydration determined by salinity (Shaki et al., 2019).

The support provided by SA to GA concentration in our experiment has been associated with better seed germination in Arabidopsis thaliana under salinity (Alonso-Ramírez et al., 2009). This suggests that GA biosynthesis and activity may be facilitated by SA, indicating another connection in the complex mechanism of hormonal interactions.

Abscisic acid is a major stress hormone acting in the internal signalling, enabling plants to survive under adverse conditions (Keskin et al., 2010). ABA is also associated with regulation of plant RWC, stomata guard cell activity, and promotion of gene induction (Zhu, 2002). SA and ABA have the same roles in stomata closing through diverse pools of ROS; based on this, SA and ABA may have positive or negative interactions depending on specific conditions (Jayakannan et al., 2015). In A. thaliana, the higher endogenous SA reduced stomata aperture and increased salinity tolerance, demonstrating a beneficial SA role in response to salt stress (Miura et al., 2013). In our experiment, SA reduced ABA accumulation, which is consistent with previous studies on maize (Fahad and Bano, 2012) and A. thaliana (Asensi-Fabado and Munné-Bosch, 2011; Miura et al., 2011): higher SA concentration increased salinity tolerance by suppressing the ABA signalling triggered by salinity.

Ethylene plays a major role in seed germination, growth, yield, and various physiological processes (Hussain et al., 2019; Ahmed et al., 2020), including root elongation and root hair formation in association with IAA (Muday et al., 2012). Salinity strongly increased ethylene production (Figure 4), resulting in depressed 
plant growth, increased ROS production and adverse physiological consequences (Steffens, 2014; Hussain et al., 2020b). Conversely, SA application considerably reduced ethylene production (Figure 4), resulting in significant improvement in growth and physiological traits. It is evinced, therefore, that the tight control of ethylene production is crucial for plant survival under salt stress, to which aim SA plays a beneficial role.

Ion uptake and translocation is highly influenced by salinity, in strong interaction with SA (Table 2 and Figure 5): SA counters $\mathrm{Na}$ and $\mathrm{Cl}$ accumulation while enhancing $\mathrm{Ca}, \mathrm{K}$ and $\mathrm{Mg}$ accumulation, as means to contrast the former two elements' noxious effects (Gunes et al., 2007; Fahad and Bano, 2012). Salinity tolerance is often associated with plant attitude to exclude $\mathrm{Na}$ in favour of $\mathrm{K}$ uptake, thus maintaining optimum $\mathrm{K} / \mathrm{Na}$ ratio (Malekzadeh, 2015). The analogous exclusion of $\mathrm{Cl}$ determined by SA suggests that a similar process might involve anions.

Excessive $\mathrm{Na}$ accumulation in cell cytosol increases ROS production, in turn affecting membrane stability by increased MDA content, EL, and protein degradation (Gao et al., 2015). Additionally, excessive $\mathrm{Na}$ affects cytosolic activities by physiological and bio-chemical changes (Flowers and Flowers, 2005), resulting in reduced carbon assimilation and premature leaf senescence (Suzuki et al., 2014). Salt stress increases EL owing to increased $\mathrm{K}$ efflux from the cells under osmotic stress. To contrast it, SA application reduces EL (Jayakannan et al., 2013) and helps the plant to retain a larger share of $\mathrm{K}$ to counter-balance $\mathrm{Na}$ excess.

Overall, the maintenance of cytosolic ion homeostasis is fundamental for plant survival under salt stress. SA application increases the defence system activities by reducing cytosolic $\mathrm{Na}$ content, while enhancing gene expression responsible for $\mathrm{Na}$ sequestration into the vacuole (Shaki et al., 2019). SA also modulates $\mathrm{Na}$ transport activities. Therefore, the reduction in Na concentration with SA application (Table 2) could be due, beside K enhancement, to Ca-mediated increase in the activity of $\mathrm{H}^{+}$ATPase, which provides the energy to remove the excessive $\mathrm{Na}$ from cells (Hoang et al., 2020).

The comprehensive effect of SA under salinity may be evinced from the PCA (Figure 6). Although the first PC that represents salinity owns a higher amount of explained variance $(82.3 \%)$, the second PC that represents SA demonstrates SA ability to enhance an array of compounds as a hormone (IAA), two antioxidant enzymes (POD and vitamin C), and an osmo-regulating compound (proline) (Table 4), which are prompted to face salinity.

\section{Conclusions}

Salinity, quite expectedly caused serious constraints to maize early growth, in association with impairments in plant physiological machinery. Exogenous application of salicylic acid was able to offset to a good extent these negative effects, by triggering mitigation mechanisms as well as improving anti-oxidant, osmo-regulating and hormonal responses. Antagonism to $\mathrm{Na}$ and $\mathrm{Cl}$ entry into the plant and translocation to aboveground organs is another remarkable feature exerted by salicylic acid under salinity.

Additional studies are, nevertheless, needed to more deeply investigate the mechanisms involved in salicylic acid effects, namely salicylic acid relationship with hormones and genes involved in Na transport, plus ABA and ethylene reduction.

Lastly, salicylic acid was shown beneficial for plant growth also under non-saline condition, which makes salicylic acid useful and applicable under field conditions, provided that a consistent protocol for seed/seedling treatment is established.

\section{References}

Acharya BR, Assmann SM, 2009. Hormone interactions in stomatal function. Plant Mol. Biol. 69:451-62.

Ahmed W, Imran M, Yaseen M, Haq T, Jamshaid MU, Rukh S, Ikram RM, Ali M, Ali A, Maqbool M, Arif M, 2020. Role of salicylic acid in regulating ethylene and physiological characteristics for alleviating salinity stress on germination, growth and yield of sweet pepper. Peer J. 8:e8475.

Alonso-Ramírez A, Rodríguez D, Reyes D, Jiménez JA, Nicolás G, López-Climent M, Gómez-Cadenas A, Nicolás C, 2009. Evidence for a role of gibberellins in salicylic acid-modulated early plant responses to abiotic stress in Arabidopsis seeds. Plant Physiol. 150:1335-44.

Al-Whaibi MH, Siddiqui MH, Basalah MO, 2012. Salicylic acid and calcium-induced protection of wheat against salinity. Protoplasma 249:769-78.

Arnon DI, 1949. Copper enzymes in isolated chloroplasts. Polyphenoloxidase in Beta vulgaris. Plant Physiol. 24:1-10.

Asada K, 1987. Production and scavenging of active oxygen in photosynthesis. Photoinhib. 4:227-87.

Asensi-Fabado MA, Munné-Bosch S, 2011. The aba3-1 mutant of Arabidopsis thaliana withstands moderate doses of salt stress by modulating leaf growth and salicylic acid levels. J. Plant Growth Regul. 30:456-66.

Ashraf M, Akram NA, Arteca RN, Foolad MR, 2010. The physiological, biochemical and molecular roles of brassinosteroids and salicylic acid in plant processes and salt tolerance. Crit. Rev. Plant Sci. 29:162-90.

Ashraf MPJC, Harris PJC, 2004. Potential biochemical indicators of salinity tolerance in plants. Plant Sci. 166:3-16.

Bates LS, Waldren RP, Teare ID, 1973. Rapid determination of free proline for water-stress studies. Plant Soil 39:205-7.

Berríos J, Illanes A, Aroca G, 2004. Spectrophotometric method for determining gibberellic acid in fermentation broths. Biotech. Letter 26:67-70.

Bradford MM, 1976. A rapid and sensitive method for the quantitation of microgram quantities of protein utilizing the principle of protein-dye binding. Ann. Biochem. 72:248-54.

Cassaniti C, Romano D, Hop MC, Flowers TJ, 2013. Growing floricultural crops with brackish water. Environ. Exper. Bot. 92:165-75.

Deinlein U, Stephan AB, Horie T, Luo W, Xu G, Schroeder JI, 2014. Plant salt-tolerance mechanisms. Trends Plant Sci. 19:371-9.

Dempsey DMA, Klessig DF, 2017. How does the multifaceted plant hormone salicylic acid combat disease in plants and are similar mechanisms utilized in humans? BMC Biol. 15:1-11.

El-Mergawi RA, El-Wahed MS, 2020. Effect of exogenous salicylic acid or indole acetic acid on their endogenous levels, germination, and growth in maize. Bull. Nat. Res. Centre 44:1-8.

El-Saidi MT, 1997. Salinity and its effect on growth, yield and some physiological processes of crop plants. In: P.K. Jaiwal, R.P. Singh, A. Gulati (Eds.), Strategies for improving salt tolerance in higher plants. Enfield, NH Science, USA, pp 111-27.

El-Tayeb MA, 2005. Response of barley grains to the interactive effect of salinity and salicylic acid. Plant Growth Reg. 45:215-24.

Eraslan F, Inal A, Gunes A, Alpaslan M, 2007. Impact of exogenous salicylic acid on the growth, antioxidant activity and physiology of carrot plants subjected to combined salinity and boron toxicity. Sci. Hort. 113:120-8.

Escobar H, Bustos R, Fernández F, Cárcamo H, Silva H, Frank N, Cardemil L, 2010. Mitigating effect of salicylic acid and nitrate on water relations and osmotic adjustment in maize, cv. 
lluteño exposed to salinity. Cien. Invest. Agr. 37:71-81.

Fahad S, Bano A, 2012. Effect of salicylic acid on physiological and biochemical characterization of maize grown in saline area. Pak. J. Bot. 44:1433-8.

FAO (Food and Agriculture Organization of the United Nations), 2019. Food and Agriculture Data. Avaliable from: http://www.fao.org/faostat

Faried HN, Ayyub CM, Amjad M, Ahmed R, Wattoo FM, Butt M, Bashir M, Shaheen MR, Waqas MA, 2017. Salicylic acid confers salt tolerance in potato plants by improving water relations, gaseous exchange, antioxidant activities and osmoregulation. J. Sci. Food Agric. 97:1868-75.

Flowers TJ, Colmer TD, 2008. Salinity tolerance in halophytes. New Phytol. 7:945-63.

Flowers TJ, Colmer TD, 2015. Plant salt tolerance: adaptations in halophytes. Ann. Bot. 115:327-31.

Flowers TJ, Flowers SA, 2005. Why does salinity pose such a difficult problem for plant breeders? Agric. Water Manag. 78:1524.

Fox J, Weisberg S. 2018. An R companion to applied regression, third edition. Sage, Thousand Oaks CA, USA. Available from: https://socialsciences.mcmaster.ca/jfox/Books/Companion

Fu Y, Guo C, Wu H, Chen C, 2017. Arginine decarboxylase ADC2 enhances salt tolerance through increasing ROS scavenging enzyme activity in Arabidopsis thaliana. Plant Growth Reg. 83:253-63.

Gao HJ, Yang HY, Bai J, Liang XY, Lou Y, Zhang JL, Wang D, Zhang JL, Niu SQ, Chen Y, 2015. Ultrastructural and physiological responses of potato (Solanum tuberosum L.) plantlets to gradient saline stress. Front. Plant Sci. 5:787.

Gill SS, Tuteja N, 2010. Reactive oxygen species and antioxidant machinery in abiotic stress tolerance in crop plants. Plant Physiol. Biochem. 48:909-30.

Golldack D, Quigley F, Michalowski CB, Kamasani UR, Bohnert HJ, 2003. Salinity stress-tolerant and-sensitive rice (Oryza sativa L.) regulate AKT1-type potassium channel transcripts differently. Plant Mol. Biol. 51:71-81.

Guan YJ, Hu J, Wang XJ, Shao CX, 2009. Seed priming with chitosan improves maize germination and seedling growth in relation to physiological changes under low temperature stress. J. Zhejiang Uni. Sci. 10:427-33.

Gunes A, Inal A, Alpaslan M, Eraslan F, Bagcİ EG, Cİcek N, 2007. Salicylic acid induced changes on some physiological parameters symptomatic for oxidative stress and mineral nutrition in maize (Zea mays L.) grown under salinity. J. Plant Physiol. 164:728-36.

Hamid M, Khalil UR, Ashraf, MY, 2010. Salicylic acid-induced growth and biochemical changes in salt $\square$ stressed wheat. Commun. Soil Sci. Plant Anal. 41:373-89.

Hamilton PB, Van-Slyke DD, 1943. Amino acid determination with ninhydrin. J. Biol. Chem. 150:231-50.

Hayat Q, Hayat S, Irfan M, Ahmad A, 2010. Effect of exogenous salicylic acid under changing environment: a review. Environ. Exper. Bot. 68:14-25.

Hayat S, Hasan SA, Fariduddin Q, Ahmad A, 2008. Growth of tomato (Lycopersicon esculentum) in response to salicylic acid under water stress. J. Plant Inter. 3:297-304.

Hokmabadi H, Arzani K, Grierson PF, 2005. Growth, chemical composition, and carbon isotope discrimination of pistachio (Pistacia vera L.) rootstock seedlings in response to salinity. Aust. J. Agric. Res. 56:135-44.

Hoang HL, Guzman CC, Cadiz NM, Hoang TH, Tran DH, Rehman H, 2020. Salicylic acid and calcium signaling induce physiological and phytochemical changes to improve salinity tolerance in red amaranth (Amaranthus tricolor L.). J. Soil Sci.
Plant Nutr. 20:1759-69.

Hsu YT, Kao CH, 2003. Role of abscisic acid in cadmium tolerance of rice (Oryza sativa L.) seedlings. Plant Cell Environ. 26:867-74.

Husen A, Iqbal M, Sohrab SS, Ansari MKA, 2018. Salicylic acid alleviates salinity-caused damage to foliar functions, plant growth and antioxidant system in Ethiopian mustard (Brassica carinata A. Br.). Agric. Food Sci. 7:44-51.

Hussain S, Zhong C, Cao X, Bai Z, Huang J, Zhu L, Khaskheli MA, Zhang J, Jin QY, 2019. 1-Methylcyclopropene modulates physiological, biochemical, and antioxidant responses of rice to different salt stress levels. Front. Plant Sci. 10:124.

Hussain S, Huang J, Zhu C, Zhu L, Cao X, Hussain S, Ashraf M, Khaskheli MA, Kong Y, Jin Q, Li X, 2020a. Pyridoxal 5'-phosphate enhances the growth and morpho-physiological characteristics of rice cultivars by mitigating the ethylene accumulation under salinity stress. Plant Physiol. Biochem. 4:1-16.

Hussain S, Zhu C, Huang J, Huang J, Zhu L, Cao X, Nanda S, Khaskheli MA, Liang Q, Kong Y, Jin Q, Zhang J, 2020 b. Ethylene response of salt stressed rice seedlings following Ethephon and 1-methylcyclopropene seed priming. Plant Growth Reg. 92:219-31.

Hussein MM, Balbaa LK, Gaballah MS, 2007. Salicylic acid and salinity effects on growth of maize plants. Res. J. Agric. Biol. Sci. 3:321-8.

Jayakannan M, Bose J, Babourina O, Rengel Z, Shabala S, 2013. Salicylic acid improves salinity tolerance in Arabidopsis by restoring membrane potential and preventing salt-induced $\mathrm{K}^{+}$ loss via a GORK channel. J. Exp. Bot. 64: 2255-68.

Jayakannan M, Bose J, Babourina O, Rengel Z, Shabala S, 2015. Salicylic acid in plant salinity stress signalling and tolerance. Plant Growth Reg. 76:25-40.

Jini D, Joseph B, 2017. Physiological mechanism of salicylic acid for alleviation of salt stress in rice. Rice Sci. 24:97-108.

Juan M, Rivero RM, Romero L, Ruiz JM, 2005. Evaluation of some nutritional and biochemical indicators in selecting saltresistant tomato cultivars. Environ. Exp. Bot. 54:193-201.

Karlidag H, Yildirim E, Turan M, 2009. Salicylic acid ameliorates the adverse effect of salt stress on strawberry. Sci. Agric. 66:180-7.

Kaydanm D, Yagmur M, Okut N, 2007. Effects of salicylic acid on the growth and some physiological characters in salt stressed wheat (Triticum aestivum L.). Tarim. Bilim. Derg. 13:114-9.

Keskin BC, Sarikaya AT, Yuksel B, Memon AR, 2010. Abscisic acid regulated gene expression in bread wheat. Aust. J. Crop Sci. 4:617-25.

Khan MIR, Syeed S, Nazar R, Anjum NA, 2012. An insight into the role of salicylic acid and jasmonic acid in salt stress tolerance. In Phytohormones and abiotic stress tolerance in plants. Springer, Berlin, Heidelberg, pp 277-300.

KimY, Kim S, Shim IS, 2017. Exogenous salicylic acid alleviates salt-stress damage in cucumber under moderate nitrogen conditions by controlling endogenous salicylic acid levels. Hort. Environ. Biotech. 58:247-53.

Kudla J, Becker D, Grill E, Hedrich R, Hippler M, Kummer U, Parniske M, Romeis T, Schumacher K, 2018. Advances and current challenges in calcium signaling. New Phytol. 218:414-31.

Lê S, Josse J, Husson F, 2008. FactoMineR: An R package for multivariate analysis. J. Stat. Softw. 25:1-18.

Lei T, Feng H, Sun X, Dai QL, Zhang F, Liang HG, Lin HH, 2010. The alternative pathway in cucumber seedlings under low temperature stress was enhanced by salicylic acid. Plant Growth Reg. 60:35-44.

Lenth RV, Buerkner P, Herve M, Love J, Riebl H, Singmann H, 2020. Emmeans: estimated marginal means, aka least squares 
means. $\mathrm{R}$ pack Available from: https://cran.rproject.org/web/packages/emmeans/index.html

Li T, Hu Y, Du X, Tang H, Shen C, Wu J, 2014. Salicylic acid alleviates the adverse effects of salt stress in Torreya grandis cv. Merrillii seedlings by activating photosynthesis and enhancing antioxidant systems. PLoS One. 9:e109492.

Lutts S, Kinet JM, Bouharmont J, 1996. NaCl-induced senescence in leaves of rice (Oryza sativa L.) cultivars differing in salinity resistance. Ann. Bot. 78:389-98.

Malekzadeh P, 2015. Influence of exogenous application of glycinebetaine on antioxidative system and growth of saltstressed soybean seedlings (Glycine max L.). Plant Physiol. Mol. Biol. 21:225-32.

Melgar JC, Benlloch M, Fernández-Escobar R, 2006. Calcium increases sodium exclusion in olive plants. Sci. Hort. 109:303-5.

Miura K, Okamoto H, Okuma E, Shiba H, Kamada H, Hasegawa PM, Murata Y, 2013 SIZ1 deficiency causes reduced stomatal aperture and enhanced drought tolerance via controlling salicylic acid-induced accumulation of reactive oxygen species in Arabidopsis. Plant J. 73:91-104.

Miura K, Sato A, Ohta M, Furukawa J, 2011. Increased tolerance to salt stress in the phosphate-accumulating Arabidopsis mutants siz1 and pho2. Planta 234:1191-9.

Mostofa MG, Fujita M, 2013. Salicylic acid alleviates copper toxicity in rice (Oryza sativa L.) seedlings by up-regulating antioxidative and glyoxalase systems. Ecotoxicol. 22:959-73.

Muday GK, Rahman A, Binder BM, 2012. Auxin and ethylene: collaborators or competitors? Trends Plant Sci. 17:181-95.

Mukherjee SP, Choudhuri MA, 1983. Implications of water stressinduced changes in the levels of endogenous ascorbic acid and hydrogen peroxide in Vigna seedlings. Plant Physiol. 58:16670 .

Munns R, 2002. Comparative physiology of salt and water stress. Plant Cell Environ. 25:239-50.

Munns R, Tester M, 2008. Mechanisms of salinity tolerance. Ann. Rev. Plant Biol. 59:651-81.

Nie W, Gong B, Chen Y, Wang J, Wei M, Shi Q, 2018. Photosynthetic capacity, ion homeostasis and reactive oxygen metabolism were involved in exogenous salicylic acid increasing cucumber seedlings tolerance to alkaline stress. Sci. Hort. 235:413-23.

Parida AK, Das AB, 2005. Salt tolerance and salinity effects on plant: a review. Ecotoxicol. Environ. Saf. 60:324-49.

Qadir M, Quillerou E, Nangia V, Murtaza G, Singh M, Thomas RJ, Drechsel P, Noble AD, 2014. Economics of salt-induced land degradation and restoration. Nat. Res. Forum 38:282-95.

Rahneshan Z, Nasibi F, Moghadam AA, 2018. Effects of salinity stress on some growth, physiological, biochemical parameters and nutrients in two pistachio (Pistacia vera L.) rootstocks. J. Plant Inter. 13:73-82.

Rao KM, Sresty TVS, 2000. Antioxidative parameters in the seedlings of pigeonpea (Cajanus cajan (L.) Millspaugh) in response to Zn and Ni stresses. Plant Sci. 157:113-28.

Raza SH, Athar HR, Ashraf M, Hameed A, 2007. Glycinebetaineinduced modulation of antioxidant enzymes activities and ion accumulation in two wheat cultivars differing in salt tolerance. Environ. Exper. Bot. 60:368-76.

Rhoades JD, Kandiah A, Mashali AM, 1992. The use of saline waters for crop production. FAO Drainage and Irrigation Paper 48. Food and Agriculture Organization of the United Nations (FAO), Rome.
Sarkar A, Ghosh PK, Pramanik K, Mitra S, Soren T, Pandey S, Mondal MH, Maiti TK, 2018. A halotolerant Enterobacter sp. Displaying ACC deaminase activity promotes rice seedling growth under salt stress. Microbiol. Res. 169:20-32.

Shaki F, Maboud HE, Niknam V, 2019. Effects of salicylic acid on hormonal cross talk, fatty acids profile, and ions homeostasis from salt-stressed safflower. J. Plant Inter. 14:340-6.

Shakirova FM, Sakhabutdinova AR, Bezrukova MV, Fatkhutdinova RA, Fatkhutdinova DR, 2003. Changes in the hormonal status of wheat seedlings induced by salicylic acid and salinity. Plant Sci. 164:317-22.

Shao Q, Wang H, Guo H, Zhou A, Huang Y, Sun Y, Li M, 2014. Effects of shade treatments on photosynthetic characteristics, chloroplast ultrastructure, and physiology of Anoectochilus roxburghii. PLoS One. 9:e85996.

Sharma P, 2013. Salicylic acid: a novel plant growth regulator role in physiological processes and abiotic stresses under changing environments. Clim. Change Plant Abiotic Stress Tol. 4:939-90.

Steel RGD, Torrie JH, Dickey D, 1997. Principles and procedures of statistics: a biometric approach, 3rd edition. McGraw-Hill Book Co., New York, NY, USA, pp 663-6.

Steffens B, 2014. The role of ethylene and ROS in salinity, heavy metal, and flooding responses in rice. Front. Plant Sci. 5:685.

Stevens J, Senaratna T, Sivasithamparam K, 2006. Salicylic acid induces salinity tolerance in tomato (Lycopersicon esculentum cv. Roma): associated changes in gas exchange, water relations and membrane stabilisation. Plant Growth Reg. 49:77-83.

Sudhir P, Murthy SDS, 2004. Effects of salt stress on basic processes of photosynthesis. Photosyn. 42:481-6.

Sun P, Tian QY, Zhao MG, Dai XY, Huang JH, Li LH, Zhang WH, 2007. Aluminum-induced ethylene production is associated with inhibition of root elongation in Lotus japonicus L. Plant Cell Physiol. 48:1229-35.

Suzuki N, Rivero RM, Shulaev V, Blumwald E, Mittler R, 2014. Abiotic and biotic stress combinations. New Phytol. 203:3243.

Velikova V, Yordanov I, Edreva A, 2000. Oxidative stress and some antioxidant systems in acid rain-treated bean plants: protective role of exogenous polyamines. Plant Sci. 151:59-66.

Waqas M, Yaning C, Iqbal H, Shareef M, Rehman H, Iqbal S, Mahmood S, 2019. Soil drenching of paclobutrazol: an efficient way to improve quinoa performance under salinity. Plant Physiol. 165:219-31.

Weiler EW, Jourdan PS, Conrad W, 1981. Levels of indole-3-acetic acid in intact and decapitated coleoptiles as determined by a specific and highly sensitive solid-phase enzyme immunoassay. Planta 153:561-71.

Wickham H, 2009. ggplot2: elegant graphics for data analysis. Available from: https://ggplot2.tidyverse.org/reference

Yildirim E, Turan M, Guvenc I, 2008. Effect of foliar salicylic acid applications on growth, chlorophyll, and mineral content of cucumber grown under salt stress. J. Plant Nutr. 31:593-612.

Zhang J, Jia W, Yang J, Ismail AM, 2006. Role of ABA in integrating plant responses to drought and salt stresses. Field Crop Res. 97:111-9.

Zhu JK, 2002. Salt and drought stress signal transduction in plants. Ann. Rev. Plant Physiol. Plant Mol. Biol. 53:247-73. 